\title{
Author Correction: Assembly of hundreds of novel bacterial genomes from the chicken caecum
}

\author{
Laura Glendinning ${ }^{1 *}$, Robert D. Stewart ${ }^{1}$, Mark J. Pallen ${ }^{2,3,4}$, Kellie A. Watson ${ }^{1}$ and Mick Watson ${ }^{1}$
}

The original article can be found online at https://doi.org/10.1186/ s13059-020-1947-1.

* Correspondence: laura. glendinning@roslin.ed.ac.uk ${ }^{1}$ Genetics and Genomics, The Roslin Institute and Royal (Dick) School of Veterinary Studies, University of Edinburgh, Edinburgh, Midlothian, UK

Full list of author information is available at the end of the article

\section{Correction to: Genome Biol 21, 34 (2020) \\ https://doi.org/10.1186/s13059-020-1947-1}

Following publication of the original paper [1], the authors have reported several typographical and linguistic errors in the new Candidatus names presented in Additional file 5: Dataset S4. In addition, the presentation of the names without full protologues has precluded their registration in the International Journal of Systematic and Evolutionary Microbiology, in line with the recommendations of the International Code of Nomenclature of Prokaryotes. The original Additional File 5 has therefore been replaced by Additional File 5A, which presents Dataset 54 with corrected names, and by Additional File 5B, which contains protologues for the new Candidatus names.

\section{Supplementary Information}

The online version contains supplementary material available at https://doi.org/10.1186/s13059-021-02284-4.

Additional file $5 \mathrm{~A}$ : Clustering of samples at 60\% AAl to form genus clusters. Novel genera were defined as clusters of MAGs at $60 \%$ AAl which were not assigned a genus by GTDB-Tk. B: Protologues for the new Candidatus names.

\section{Author details}

The online version contains supplementary material available at https://doi.org/10.1186/s13059-021-02284-4. ${ }^{1}$ Genetics and Genomics, The Roslin Institute and Royal (Dick) School of Veterinary Studies, University of Edinburgh, Edinburgh, Midlothian, UK. ${ }^{2}$ Microbes in the Food Chain, Quadram Institute Bioscience, Norwich, UK. ${ }^{3}$ School of Biological Sciences, University of East Anglia, Norwich, Norfolk, UK. ${ }^{4}$ School of Veterinary Medicine, University of Surrey, Guildford, Surrey, UK.

Published online: 12 February 2021

\section{Reference}

1. Glendinning L, Stewart RD, Pallen MJ, et al. Assembly of hundreds of novel bacterial genomes from the chicken caecum. Genome Biol. 2020;21:34 https://doi.org/10.1186/s13059-020-1947-1. 